\section{Diagnostic accuracy of ultrasound for rotator cuff tears}

\author{
Kelechi R. Okoroha', Mohsin S. Fidai', Joseph S. Tramer ${ }^{1}$, Kayla D. Davis², \\ Patricia A. Kolowich ${ }^{1}$ \\ ${ }^{1}$ Department of Orthopaedic Surgery, Henry Ford Hospital, Detroit, MI; ${ }^{2}$ Hampton University, \\ Hampton, VA, USA
}

Ultrasonography (US) is an inexpensive, convenient, and effective tool that can be used to evaluate the shoulder. It does not expose the patient to harmful radiation and can be used to evaluate the musculoskeletal system dynamically. Additionally, US is not subject to metal artifacts when evaluating patients with previously placed hardware. Over the years, US has been found to be reliable and accurate for diagnosing rotator cuff tears (RCTs), despite its operatordependence. The usage of US for diagnosing RCTs in orthopedic practice varies depending on practitioners' familiarity with the exam and the availability of experienced technicians. The purpose of this article is to review the diagnostic accuracy of US for identifying RCTs.

Keywords: Ultrasound; Rotator cuff; Rotator cuff tear; Diagnostic imaging

\section{Introduction}

Rotator cuff tears (RCTs) are one of the most common causes of shoulder pain and account for nearly 4.5 million patient visits in the United States annually $[1,2]$. The incidence of RCTs increases with age, with approximately $25 \%$ of individuals over the age of 60 and $50 \%$ of individuals over 80 having experienced a full-thickness RCT [3]. Determining the integrity of the rotator cuff tendons is essential in deciding between surgical and non-surgical management [4]. In addition to a physical examination, imaging-most commonly, ultrasonography (US) or magnetic resonance imaging (MRI)-is usually necessary to diagnose an RCT [5].

Multiple studies have demonstrated that US and MRI have comparable accuracy in diagnosing RCTs before surgery, although the accuracy of US is more operator-dependent [6-11]. Although recent studies have found that experienced sonographers can provide accurate imaging, enabling the size and thickness of RCTs to be predicted, one may not always be readily available $[12,13]$. However, US is more accessible and cost-efficient than MRI. The efficiency, relatively low cost, and low risk of US make it a good initial method for detecting RCTs.

Although studies have suggested that US is an efficient tool for diagnosing full-thickness RCTs, controversy exists regarding the accuracy of US in detecting partial-thickness tears and other characteristics of RCTs $[10,14-16]$. The purpose of this article is to review the diagnostic accuracy of US for identifying RCTs, including assessments of the severity of the tear and ancillary findings such as fatty degeneration and tendon retraction.

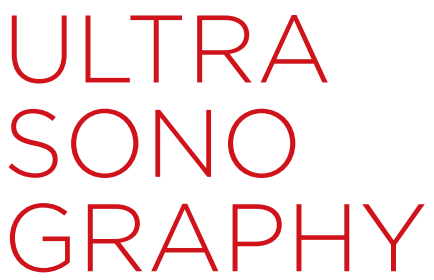

\section{REVIEW ARTICLE}

https://doi.org/10.14366/usg. 18058 pISSN: 2288-5919 • elSSN: 2288-5943 Ultrasonography 2019;38:215-220

Received: October 10, 2018

Revised: November 16, 2018

Accepted: November 17, 2018

Correspondence to:

Kelechi R. Okoroha, MD, Department of Orthopaedic Surgery, Henry Ford Hospital, 2799 West Grand Boulevard, Detroit, MI 48202, USA

Tel. +1-313-916-2600

E-mail: Krokoroha@gmail.com

This is an Open Access article distributed under the terms of the Creative Commons Attribution NonCommercial License (http://creativecommons.org/ licenses/by-nc/4.0/) which permits unrestricted noncommercial use distribution and reproduction in any medium, provided the original work is properly cited

Copyright @ 2019 Korean Society of Ultrasound in Medicine (KSUM)

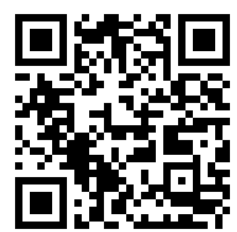

How to cite this article:

Okoroha KR, Fidai MS, Tramer JS, Davis KD, Kolowich PA. Diagnostic accuracy of ultrasound for rotator cuff tears. Ultrasonography. 2019 Jul;38(3):215-220. 


\section{Full-Thickness RCTs}

Previous studies have demonstrated the capability of US to diagnose full-thickness RCTs. In 2008, Fotiadou et al. [17] evaluated the accuracy of US in detecting full-thickness RCTs in 96 patients with clinically suspected rotator cuff pathology. The authors found that in 57 patients with arthroscopically confirmed full-thickness RCTs, US was $98 \%$ accurate in identifying the tears [17]. Similarly, Moosmayer et al. [15] reported that US correctly identified 24 of 24 full-thickness RCTs, confirmed by intraoperative findings. The accuracy of US in diagnosing RCTs has also been found to be similar to that of MRI. In 2010, Rutten et al. [18] demonstrated US and MRI to be comparably accurate in diagnosing full-thickness RCTs (94\% and $94 \%$, respectively). Fig. 1 demonstrates a full-thickness RCT on both MRI and US in the same patient.

However, published results on the sensitivity of US in detecting full-thickness RCTs vary widely. Using arthroscopy as the standard, Cowling et al. [19] found US to have high sensitivity and specificity for detecting full-thickness RCTs $(92.3 \%$ and $93.0 \%$, respectively). In contrast, Paavolainen and Ahovuo [20] recorded an overall sensitivity of $74 \%$ and specificity of $95 \%$ of US in detecting 20 fullthickness RCTs. Furthermore, Martin-Hervas et al. [16] found US to be highly specific in in diagnosing full-thickness RCTs (100\%), but not as sensitive (57.7\%). Similarly, using 3.0-T MRI as the diagnostic standard, Yazigi et al. [21] found a 100\% specificity and $46.2 \%$ sensitivity of US for full-thickness tears of the supraspinatus. These studies suggest that US has high specificity for diagnosing full-thickness RCTs. While US has high specificity and can be used to rule out an RCT if not present on US imaging, the exam is less sensitive and may not capture all tears, or the extent of the tear.

\section{Partial-Thickness RCTs}

The literature on the ability of US to accurately diagnose partialthickness RCTs is heterogeneous. In 2008, Fotiadou et al. [17] evaluated the accuracy of US in detecting partial-thickness RCTs. They found that US was $87 \%$ accurate in identifying either bursal or articular partial-thickness tears, whereas MRI was $90 \%$ accurate [17]. Similar findings were presented by Rutten et al. [18], who found US to be $81 \%$ accurate and MRI to be $84 \%$ accurate for detecting partial-thickness tears. Moosmayer et al. [15] found US to be a poor tool when radiologists were blinded to clinical presentation. In their cohort of 14 partial-thickness tears, US only correctly identified one tear as partial-thickness [15]. Using arthroscopy as the gold standard, Teeffey et al. [11] prospectively studied 71 consecutive patients with shoulder pain. There were 6 diagnostic errors in 19 patients with partial-thickness tears. In two cases, the tears were missed. In the remaining four cases, US mistakenly diagnosed fullthickness tears [11]. Fig. 2 presents a representative image of a partial articular-sided RCT with intact bursal fibers.

The sensitivity and specificity of US for diagnosing partialthickness RCTs has been found to be lower than for full-thickness RCTs. Cowling et al. [19] found that the sensitivity and specificity of US in detecting partial-thickness tears were $65.0 \%$ and $94.0 \%$,

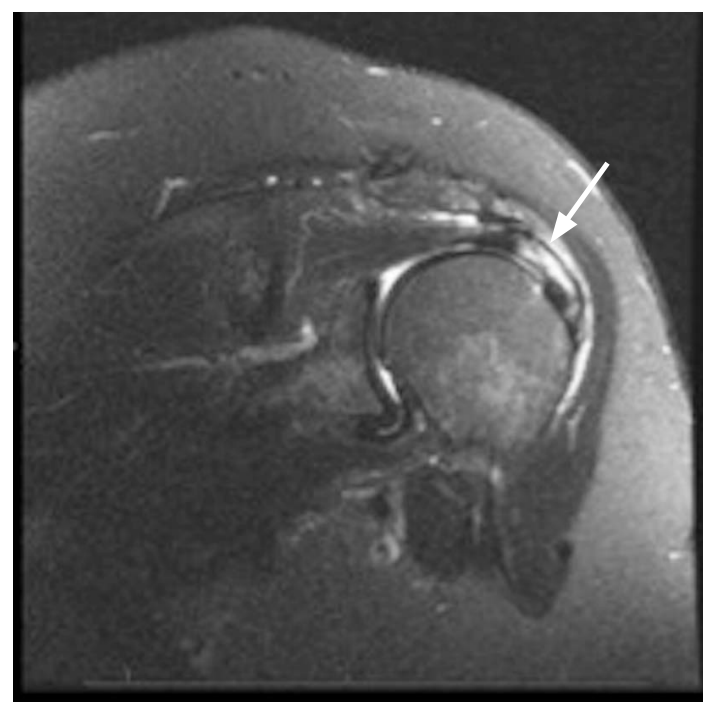

A

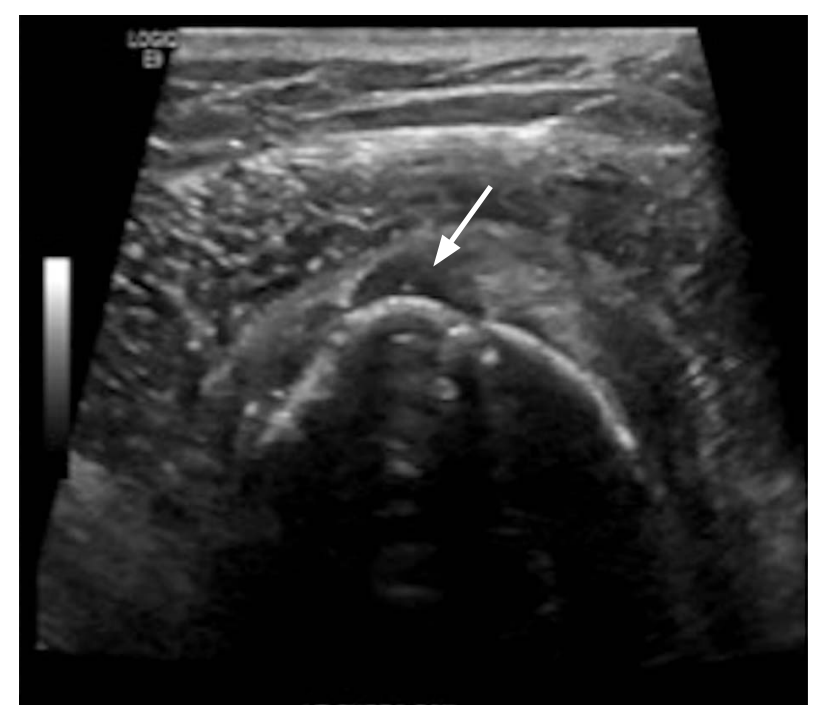

B

Fig. 1. A 65-year-old woman with a full-thickness supraspinatus tear.

T2 coronal magnetic resonance imaging (A) and coronal ultrasonography (B) show the location of the supraspinatus tear (arrows), measuring approximately $1.6 \mathrm{~cm}$. 


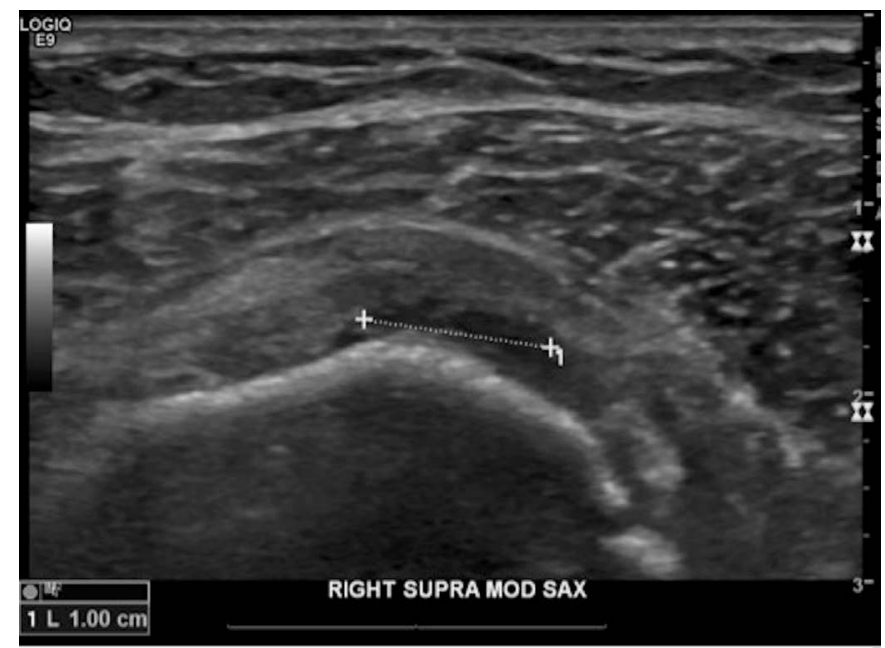

Fig. 2. A 60-year-old woman presenting with right shoulder pain. Coronal ultrasonography demonstrates a 1-cm, partial-thickness articular-sided rotator cuff tear with intact bursal fibers (dotted line).

respectively. Elmorsy et al. [22] retrospectively evaluated a cohort of 255 patients who underwent shoulder arthroscopy and compared preoperative MRI and US imaging findings to intraoperative findings. They determined that US was less sensitive than MRI for detecting partial-thickness RCTs, but not to a statistically significant extent ( $23 \%$ vs. $54.1 \%$, respectively; $P=0.333$ ). Additionally, they found US to be more specific than MRI for identifying partial-thickness RCTs $(90.1 \%$ vs. $72.6 \%$, respectively; $P<0.001)$, and therefore recommended US as the preferred diagnostic modality for RCTs at their institution [22].

Martin-Hervas et al. [16] determined US to have acceptable specificity of $67.9 \%$ for partial tears, but very low sensitivity $(12.5 \%)$, and therefore advocated for the use of MRI in addition to US for diagnosing partial RCTs in patients who have clinical signs of shoulder pathology. MRI in conjunction with US increased the sensitivity of the test to $63.6 \%$ [16]. Similarly, Sipola et al. [8] advocated for the use of MRI to confirm negative US findings in patients with signs and symptoms of a RCT who have not experienced symptom relief after 3 months of conservative treatment. These studies suggest that US has relatively low sensitivity and specificity for diagnosing partial-thickness RCTs. As the sensitivity of US for partial-thickness RCTs is low, it is possible to miss the diagnosis if the exam is used in isolation. The addition of MRI imaging to US in patients who are suspected of having partial-thickness tears increases the chances of identifying the tear. Based on this literature review, US is an appropriate method for the initial diagnostic workup of a partial-thickness tear, but MRI should be strongly considered in the event of negative US findings with continued symptoms despite conservative management or an examination that is discordant with imaging.

\section{Tear Size, Tendon Retraction, and Fatty Infiltration}

The literature shows various results regarding the ability of US, compared with other modalities, to assess characteristics of RCTs such as tear size, tendon retraction, and fatty infiltration. Some studies have shown that shoulder US was comparable to MRI for determining the size of RCTs. In an evaluation of 42 shoulders with office-based US, lannotti et al. [23] found US to have an $86 \%$ sensitivity for determining the anteroposterior dimensions of the RCTs, compared to $93 \%$ sensitivity with MRI. When evaluating tear retraction, US was found to have an $83 \%$ sensitivity while MRI was $88 \%$ sensitive [23]. In a study by Teefey et al. [9], US correctly predicted the degree of tendon retraction in $73 \%$ of full-thickness RCTs, while correctly predicting tear width in $87 \%$ of patients with full-thickness tears. That study also found that the length of partialthickness tears was correctly identified in 11 of 13 US examinations $(85 \%)$, and that most of the errors in tear retraction and width occurred in cases of massive or large RCTs [9].

The accuracy of US compared to arthroscopic findings in detecting RCT size has also been evaluated. Al-Shawi et al. [24] divided fullthickness RCTs into small $(<1 \mathrm{~cm})$, moderate $(1$ to $3 \mathrm{~cm})$, and large/ massive $(>3 \mathrm{~cm})$. The study found that the estimation of tear size was more accurate for large and massive tears (96.5\%) than for moderate (88.8\%) and small (91.6\%) tears [24]. On the contrary, another group of researchers compared the utility of MRI and US for characterizing RCTs in 114 patients [25]. That study found that MRI and US were comparable in terms of measuring tear width and retraction until the tear size approached $2 \mathrm{~cm}$; for tear sizes larger than $2 \mathrm{~cm}$, US underestimated tear width and retraction.

Additionally, that study found that the agreement between MRI and US for tear width and retraction was moderate, whereas their agreement for muscle atrophy and fatty infiltration was only slight or fair. Wall et al. [26] evaluated the diagnostic performance and reliability of US for determining fatty degeneration, using MRI as the standard. They found US to be $92.5 \%$ accurate in regard to the supraspinatus and infraspinatus and $87.5 \%$ accurate for the teres minor. The level of agreement between US and MRI for the supraspinatus and infraspinatus was relatively high (kappa $=0.76$ and kappa $=0.77$, respectively), but lower for the teres minor (kappa=0.47) [22]. Both MRI and US imaging of a single patient with fatty infiltration of the supraspinatus muscle are shown in Fig. 3. These studies suggest that although US may be adequate for identifying the presence of an RCT, the accuracy of US for categorizing characteristics of RCTs, including tear width, retraction, 


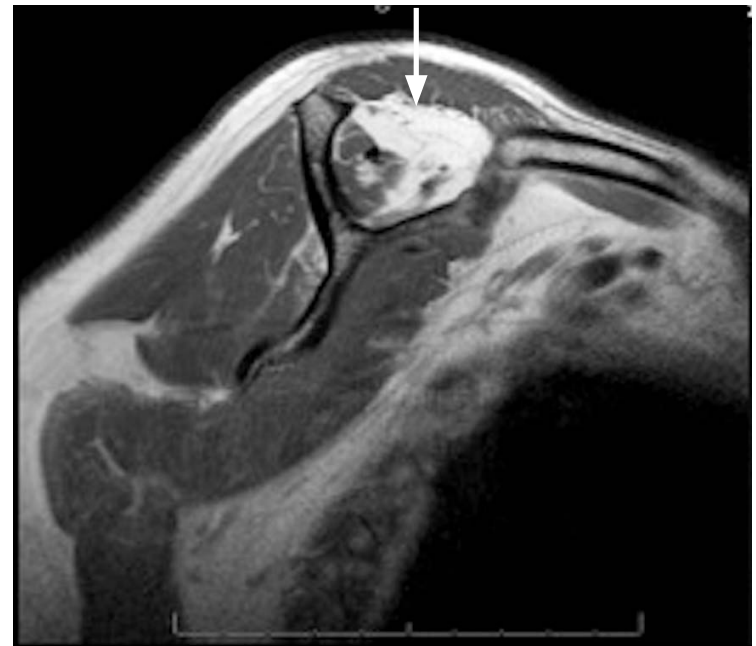

A

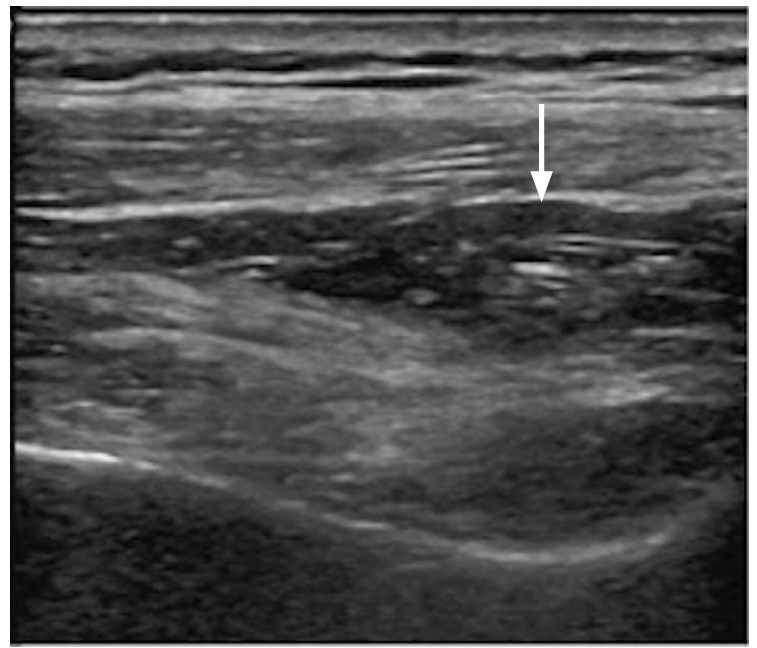

B

Fig. 3. A 76-year-old woman with a chronic full-thickness supraspinatus tear.

A. T1 sagittal magnetic resonance image shows Goutallier grade 4 fatty infiltration of the supraspinatus muscle (arrow). B. Coronal ultrasonography demonstrates the supraspinatus muscle (arrow) with areas of increased echogenicity indicative of fatty infiltration.

fatty infiltration, and muscle atrophy, can vary based on tear size.

\section{Recurrent Tears}

The diagnosis of recurrent RCTs after repair can be challenging. MRI has been shown to be relatively accurate in identifying fullthickness re-tears after surgery [27]. However, the implants used during surgical repair can cause artifacts on MRI, which may make identifying recurrent partial-thickness tears more difficult $[27,28]$. Using revision arthroscopy as the gold standard for diagnosis, Gilat et al. [29] found US to have a sensitivity of $80.8 \%$ and specificity of $100 \%$ in the diagnosis of rotator cuff re-tears. The sensitivity increased to $94.7 \%$ and $100 \%$ specificity when partial rotator cuff re-tears were omitted from the analysis [29]. Prickett et al. [30] evaluated 34 patients who underwent rotator cuff repair, and found ultrasound to be $91 \%$ sensitive and $86 \%$ specific, with an accuracy of $89 \%$, in determining rotator cuff integrity postoperatively. These studies demonstrated promising results when US was used to identify a re-tear of the rotator cuff after surgery. Full thickness retears have been shown to be easier to identify than partial thickness re-tears using US.

\section{Transducer Frequency}

Technical improvements such as $7.5-14 \mathrm{MHz}$ linear array broadbandwidth transducers and better penetration of the US beam, as well as increased experience, can significantly improve US results and reliability [31]. By using a high frequency, transducers have greatly enhanced the efficacy of US. Conducting US with highfrequency linear array transducers and high-resolution equipment has greatly increased its efficacy [32].

In a 2011 systematic review, Smith et al. [10] found superior diagnostic accuracy using 7.5 MHz compared to $10 \mathrm{MHz}$ for detecting partial RCTs. The pooled sensitivity for the $7.5 \mathrm{MHz}$ transducer was $90 \%$ ( $95 \%$ confidence interval $[\mathrm{Cl}], 87 \%$ to $93 \%$ ), whereas the $10 \mathrm{MHz}$ transducer demonstrated a pooled sensitivity of $66 \%(95 \% \mathrm{Cl}, 44 \%$ to $76 \%)$ [10].

While transducer frequency has been shown to effect the quality and accuracy of imaging, US of the rotator cuff is highly operatordependent. Small errors in transducer orientation and angulation may easily obscure small areas of normal variation within and around the cuff and give rise to false-positive and false-negative results [32]. A study evaluating surgeon-sonographer interactions found that error can come arise from three sources: the US operator obtaining the images, the interpretation of the images, and the quality of the equipment itself [33]. It is important to recognize these potential pitfalls when using US as a primary imaging modality.

\section{Ultrasound Technicians}

The experience of the sonographer and reviewer is a key factor in inter- and intra-observer reliability $[10,12,13,34]$. There is a steep learning curve when performing and interpreting US of the rotator cuff, with the number of US exams and frequency of US use directly correlating with accuracy [35]. Those learning to interpret the rotator 
cuff using US should follow a curriculum such as that recently updated by the American Medical Society for Sports Medicine [23]. Interestingly, surgeon-sonographer interaction has been shown to improve the diagnostic utility of US [33]. lannotti et al. [23] found that US was $52 \%$ accurate for blinded interpretation, compared to $80 \%$ when US was combined with clinical information.

The profession of the operator has also been shown to influence the sensitivity and specificity of US in detecting RCTs. A systematic review and meta-analysis of 62 studies found that the diagnostic accuracy of US was greatest when performed by a musculoskeletal radiologist, followed by orthopedic surgeons. General radiologists without a particular interest in musculoskeletal radiology and sonographers had lower levels of accuracy [10].

\section{Summary}

US is an effective diagnostic tool for evaluating rotator cuff tendon pathology. As shown in the literature, US is accurate for detecting full-thickness RCTs. However, in patients with negative US findings for a full-thickness RCT but high clinical suspicion, MRI should be utilized to further evaluate the integrity of the rotator cuff. US is less accurate for diagnosing partial-thickness RCTs. In the evaluation of a patient with a suspected partial-thickness RCT who has persistent symptoms despite conservative treatment, an MRI scan should be obtained to identify the source of symptoms.

For evaluating the characteristics of RCTs, US may be less accurate than MRI. Although US has shown good accuracy in determining whether a tear is present, MRI may be more suitable for determining tear size, tendon retraction, muscle atrophy, and the degree of fatty infiltration. In evaluating patients with recurrent shoulder pain after a rotator cuff repair, US has been found to be an accurate tool in diagnosing re-tears, while limiting interference from orthopedic hardware.

US equipment and operator experience have also been identified as factors that affect the accuracy of US in identifying RCTs. Generally, it is recommended that a $7.5-\mathrm{MHz}$ transducer should be used and that a musculoskeletal radiologist should perform and interpret the findings of the study. Communication of clinical findings between the surgeon and radiologist has been shown to improve the accuracy of US for evaluating the rotator cuff.

ORCID: Kelechi R. Okoroha: https://orcid.org/0000-0002-2780-3159

\section{Conflict of Interest}

No potential conflict of interest relevant to this article was reported.

\section{References}

1. Oh LS, Wolf BR, Hall MP, Levy BA, Marx RG. Indications for rotator cuff repair: a systematic review. Clin Orthop Relat Res 2007; 455:52-63.

2. Lazarides AL, Alentorn-Geli E, Choi JH, Stuart JJ, Lo IK, Garrigues $\mathrm{GE}$, et al. Rotator cuff tears in young patients: a different disease than rotator cuff tears in elderly patients. J Shoulder Elbow Surg 2015;24:1834-1843.

3. Yamaguchi K, Ditsios K, Middleton WD, Hildebolt CF, Galatz LM, Teefey SA. The demographic and morphological features of rotator cuff disease: a comparison of asymptomatic and symptomatic shoulders. J Bone Joint Surg Am 2006;88:1699-1704.

4. Blanchard TK, Bearcroft PW, Constant CR, Griffin DR, Dixon AK. Diagnostic and therapeutic impact of MRI and arthrography in the investigation of full-thickness rotator cuff tears. Eur Radiol 1999;9:638-642.

5. Lenza M, Buchbinder R, Takwoingi Y, Johnston RV, Hanchard NC, Faloppa F. Magnetic resonance imaging, magnetic resonance arthrography and ultrasonography for assessing rotator cuff tears in people with shoulder pain for whom surgery is being considered. Cochrane Database Syst Rev 2013;(9):CD009020.

6. de Jesus JO, Parker L, Frangos AJ, Nazarian LN. Accuracy of MRI, MR arthrography, and ultrasound in the diagnosis of rotator cuff tears: a meta-analysis. AJR Am J Roentgenol 2009;192:1701-1707.

7. Friedman RL, Hidalgo HJ, Gilmer PW, Mallon WJ. Ultrasonography of the rotator cuff: Analysis of results in a community setting. J Shoulder Elbow Surg 1993;2:22-26.

8. Sipola P, Niemitukia L, Kroger H, Hofling I, Vaatainen U. Detection and quantification of rotator cuff tears with ultrasonography and magnetic resonance imaging: a prospective study in 77 consecutive patients with a surgical reference. Ultrasound Med Biol 2010;36:1981-1989.

9. Teefey SA, Rubin DA, Middleton WD, Hildebolt CF, Leibold RA, Yamaguchi K. Detection and quantification of rotator cuff tears: comparison of ultrasonographic, magnetic resonance imaging, and arthroscopic findings in seventy-one consecutive cases. J Bone Joint Surg Am 2004;86:708-716.

10. Smith TO, Back T, Toms AP, Hing CB. Diagnostic accuracy of ultrasound for rotator cuff tears in adults: a systematic review and meta-analysis. Clin Radiol 2011;66:1036-1048.

11. Teefey SA, Middleton WD, Payne WT, Yamaguchi K. Detection and measurement of rotator cuff tears with sonography: analysis of diagnostic errors. AJR Am J Roentgenol 2005;184:1768-1773.

12. Goldberg JA, Bruce WJ, Walsh W, Sonnabend DH. Role of community diagnostic ultrasound examination in the diagnosis of full-thickness rotator cuff tears. ANZ J Surg 2003;73:797-799.

13. Chang CY, Wang SF, Chiou HJ, Ma HL, Sun YC, Wu HD. Comparison of shoulder ultrasound and MR imaging in diagnosing full-thickness 
rotator cuff tears. Clin Imaging 2002;26:50-54.

14. Vlychou M, Dailiana Z, Fotiadou A, Papanagiotou M, Fezoulidis IV, Malizos K. Symptomatic partial rotator cuff tears: diagnostic performance of ultrasound and magnetic resonance imaging with surgical correlation. Acta Radiol 2009;50:101-105.

15. Moosmayer S, Heir S, Smith HJ. Sonography of the rotator cuff in painful shoulders performed without knowledge of clinical information: results from 58 sonographic examinations with surgical correlation. J Clin Ultrasound 2007;35:20-26.

16. Martin-Hervas C, Romero J, Navas-Acien A, Reboiras JJ, Munuera L. Ultrasonographic and magnetic resonance images of rotator cuff lesions compared with arthroscopy or open surgery findings. J Shoulder Elbow Surg 2001;10:410-415.

17. Fotiadou AN, Vlychou M, Papadopoulos P, Karataglis DS, Palladas P, Fezoulidis IV. Ultrasonography of symptomatic rotator cuff tears compared with MR imaging and surgery. Eur J Radiol 2008;68:174179.

18. Rutten MJ, Spaargaren GJ, van Loon T, de Waal Malefijt MC, Kiemeney LA, Jager GJ. Detection of rotator cuff tears: the value of MRI following ultrasound. Eur Radiol 2010;20:450-457.

19. Crowling P, Gamble A, Rangan A. The use of shoulder ultrasound in a one-stop clinic: diagnostic accuracy for rotator cuff tear and biceps tendon pathology. Shoulder Elbow 2017;3:13-16.

20. Paavolainen P, Ahovuo J. Ultrasonography and arthrography in the diagnosis of tears of the rotator cuff. J Bone Joint Surg Am 1994;76:335-340.

21. Yazigi JA Jr, Nicolao FA, Matsunaga FT, Archetti Netto N, Matsumoto MH, Tamaoki MJ. Sensitivity and specificity of ultrasonography in diagnosing supraspinatus lesions: a prospective accuracy diagnostic study. Sao Paulo Med J 2018;136:292-297.

22. Elmorsy A, Keightley A, Flannery M. Accuracy of ultrasonography (US) and magnetic resonance imaging (MRI) in detection of rotator cuff tears in district general hospital. Pol J Radiol 2017;82:634-637.

23. Iannotti JP, Ciccone J, Buss DD, Visotsky JL, Mascha E, Cotman K, et al. Accuracy of office-based ultrasonography of the shoulder for the diagnosis of rotator cuff tears. J Bone Joint Surg Am 2005;87:13051311.

24. Al-Shawi A, Badge R, Bunker T. The detection of full thickness rotator cuff tears using ultrasound. J Bone Joint Surg $\mathrm{Br}$ 2008;90:889-892.

25. Okoroha KR, Mehran N, Duncan J, Washington T, Spiering T, Bey MJ, et al. Characterization of rotator cuff tears: ultrasound versus magnetic resonance imaging. Orthopedics 2017;40:e124-e130.

26. Wall LB, Teefey SA, Middleton WD, Dahiya N, Steger-May K, Kim $H M$, et al. Diagnostic performance and reliability of ultrasonography for fatty degeneration of the rotator cuff muscles. J Bone Joint Surg Am 2012;94:e83.

27. Magee TH, Gaenslen ES, Seitz R, Hinson GA, Wetzel LH. MR imaging of the shoulder after surgery. AJR Am J Roentgenol 1997; 168:925-928.

28. Owen RS, lannotti JP, Kneeland JB, Dalinka MK, Deren JA, Oleaga L. Shoulder after surgery: MR imaging with surgical validation. Radiology 1993;186:443-447.

29. Gilat $R$, Atoun $E$, Cohen $O$, Tsvieli O, Rath E, Lakstein $D$, et al. Recurrent rotator cuff tear: is ultrasound imaging reliable? J Shoulder Elbow Surg 2018;27:1263-1267.

30. Prickett WD, Teefey SA, Galatz LM, Calfee RP, Middleton WD, Yamaguchi K. Accuracy of ultrasound imaging of the rotator cuff in shoulders that are painful postoperatively. J Bone Joint Surg Am 2003;85:1084-1089.

31. Naqvi GA, Jadaan M, Harrington P. Accuracy of ultrasonography and magnetic resonance imaging for detection of full thickness rotator cuff tears. Int J Shoulder Surg 2009;3:94-97.

32. Bashir S, Firdose SR, Kamal $Y$, Khan HA, Arora M, Gul S, et al. Correlation between high resolution ultrasonography and MRI in rotator cuff tear diagnosis. Int J Health Sci Res 2014;4:103-112.

33. Kurz AZ, Kelly MJ, Hackett L, Murrell GA. Effect of surgeonsonographer interaction on ultrasound diagnosis of rotator cuff tears: a five-year cohort study in 775 shoulders. J Shoulder Elbow Surg 2016;25:1385-1394.

34. Mack LA, Gannon MK, Kilcoyne RF, Matsen RA 3rd. Sonographic evaluation of the rotator cuff. Accuracy in patients without prior surgery. Clin Orthop Relat Res 1988;(234):21-27.

35. McCulloch RA, McBride T, Choudhury Z, Armitstead C, Simons AW. Surgeon-lead shoulder ultrasound for rotator cuff tears, accuracy and learning curve. Shoulder Elbow 2012;5:30-32. 